\section{Cartografía Social, cartografías y multiplicidad. Producir método desde las trayectorias en Patagonia Central}

\author{
Juan Manuel Diez Tetamanti \\ Universidad Nacional de la Patagonia \\ San Juan Bosco, Argentina. \\ Consejo Latinoamericano de Ciencias \\ Sociales (CLACSO). \\ Consejo Nacional de Investigaciones \\ Científicas y Técnicas (CONICET). \\ mdiezte@gmail.com
}

Investigación y extensión universitaria / Intervenciones
RECEPCIÓN: 29/07/18

ACEPTACIÓN FINAL: 26/10/18

\section{Resumen}

La extensión universitaria suma preguntas. Puede sumarlas a partir de una mirada distante o bien incluirlas en procesos que están marcha: implicarse y producir esas preguntas colectivamente. Este trabajo deambula entre varios territorios, produciendo nuevos sentidos. Los sentidos se producen con el otro y no sobre el otro, principio sobresaliente en la "pesquisa cartográfica". El texto revisa un proceso de producción metodológica y de productos de investigación e implicación desde proyectos de extensión en Patagonia Central. Cada lugar en ese proceso, constituyó una marca que sumó aprendizajes, deseos y preguntas para poder continuar. Como en un proyecto indeterminado, la investigación social se abre las puertas entre lo múltiple, navega diferentes experiencias y toma de ellas calcos que se pondrán en función en una próxima experiencia mientras sufre transformaciones. Así, experiencia, método e implicación desembarcan en Cartografía Social como método que reúne estas perspectivas para ponerlas en función sobre planos comunes: el mapa en blanco. Desde allí, se producirán nuevos sentidos, nuevas preguntas y, así, estaremos convidados a una permanente deriva de investigación.

Palabras clave: Cartografía Social, experiencia, investigación, implicación, Patagonia.
Social Cartography, cartographies and multiplicity. Produce method from trajectories in Central Patagonia

\section{Abstract}

The university extension adds questions. You can add them from a distant view, or include them in processes that are ongoing: get involved and produce those questions collectively. This work wanders between several territories, producing new senses. The senses are produced "with the other" and not "over the other", an outstanding principle in the "cartographic research". The text reviews a process of methodological production and research and implication products, from extension projects in Central Patagonia. Each place in that process constituted a brand, which added learning, wishes and questions to be able to continue. As in an indeterminate project, social research opens the doors between the multiple, navigating different experiences and taking from them traces that will be put into operation in a future experience, while will suffer transformations. So, experience, implication and transformation, disembark in Social Cartography as a method that gathers these perspectives to put them in function on common planes: the blank map. From there, new senses will be produced, new questions and, thus, we will be invited in a permanent drift of investigation.

Keywords: Social Cartography, experience, investigation, implication, Patagonia.
Cartografia Social, cartografias e multiplicidade. Produzir método a partir de trajetórias na Patagônia Central

\section{Resumo}

A extensão universitária adiciona perguntas. Pode adicioná-las a partir de uma visão distante ou incluí-las em processos em andamento: comprometer-se e produzir essas perguntas coletivamente. Este trabalho deambula entre vários territórios, produzindo novos sentidos. Os sentidos são produzidos "com o outro" e não "sobre o outro", um princípio da "pesquisa cartográfica". O texto revisa um processo de produção metodológica e produtos de pesquisa e implicação, a partir de projetos de extensão na Patagônia Central. Cada lugar nesse processo constituiu uma marca, que acrescentou aprendizagem, desejos e perguntas para poder continuar. Como em um projeto indeterminado, a pesquisa social abre suas portas entre a multiplicidade, navegando diferentes experiências e tirando delas cópias que funcionarão em uma experiência futura, enquanto passam por transformações. Assim, experiência, implicação e devir, desembarcam na Cartografia Social como um método que reúne estas perspectivas para colocá-las em funcionamento em planos comuns: o mapa em branco. A partir daí, serão produzidos novos sentidos, novas perguntas e, assim, seremos convidados a uma permanente deriva de pesquisa.

Palavras chave: Cartografia Social, experiência, pesquisa, implicação, Patagônia.

Para citación de este artículo: Diez Tetamanti, J.M. (2018). Cartografía Social, cartografías y multiplicidad. Producir método desde las trayectorias en Patagonia Central. +E: Revista de Extensión Universitaria, 8(9), julio-diciembre, 145-156. doi: 10.14409/extension.v8i9.Jul-Dic.7852. 
"Caminante, no hay camino se hace

camino al andar."

\section{Estamos perdidos}

Recorrer un proceso implica una selección de acontecimientos a relatar y argumentar. El recorrido es un acto permanente de omisiones entre aquello que queda afuera en los límites impuestos por el relato y de selección de aquello que incluimos. En este caso, la construcción de un "tema de implicación e investigación", la producción de un tema de investigación implicado, es aquello que Francesco Careri (2014) llama "proyecto indeterminado". Y que está íntimamente asociado al "andar" como práctica desde la cual se experimenta, se conoce y, en algunos casos, se interviene el espacio.

Desde 2011 venimos andando en lo que algunos autores llaman Patagonia Central (Bondel y Vázquez, 2016). ¿Pero qué es lo central de Patagonia? ¿Dónde está puesta la marca que dice desde y hasta aquí? Y en este proyecto indeterminado que hemos decidido emprender grupalmente, optamos también por la desorientación ontológica. Así, en el propio método, la errancia es clave del hallazgo. En palabras de Heidegger:

"sin el errar no existiría ninguna relación de destino a destino, no habría historia. Las distancias cronológicas y las series causales pertenecen, sin duda, a la ciencia histórica, pero no son la historia. Cuando somos históricamente, no estamos ni a una pequeña ni a una gran distancia de lo griego. Pero nos hallamos en el errar en relación con él”. (1984:250)

Tampoco esas distancias que transitamos en esta parte de la Patagonia están dispuestas con la exactitud que enarbola lo cartesiano, pues es en el propio extravío, desde la perspectiva heideggeriana, en donde está el hallazgo.

En este texto presentamos el proceso como un andar errante, indeterminado y de encuentros, desde donde indefectiblemente construimos una historia de prácticas, traducciones, producciones de territorio y siembras de nuevos modos de hacer colectivo. Comentaremos brevemente las influencias teóricas y metodológicas con las cuales comenzamos a abordar Cartografía Social, al tiempo que tres diferentes encuentros en talleres (en Comodoro Rivadavia, Río Mayo y Aldea Beleiro) nos permitirán identificar las marcas que propiciaron aportes metodológicos al modo de abordaje de Cartografía Social que proponemos desde la Cátedra Libre de Cartografía Social de la Universidad Nacional de la Patagonia San Juan Bosco.

\section{Territorios, territorios flotantes y sujetos entre los límites}

Tomamos la idea de territorios flotantes de Fernando Aínsa y que refiere a la dificultad de catalogar, identificar, discriminar identidades en la producción de la literatura latinoamericana dado que hay una "nueva cartografía de la pertenencia" (2014:113), la cual responde a un proceso permanente de desterritorialización y territorialización del sujeto en el sentido deleuziano (Deleuze y Guattari, 1977). Tomamos territorios flotantes en sincronización con la noción de cartografía de Deleuze y Guattari, que implica la producción de una serie de flujos, codificaciones y dinámicas que singularizan una territorialidad que no es precisamente aquella que traemos de la Geografía tradicional o las ciencias más duras y analíticas. Territorio es, 
para nosotros, siempre subjetivo, yuxtapuesto y singular. Así, no hablaremos de "un" territorio sino de múltiples territorios coexistentes, tantos como sujetos lo padecen en cuerpo. En este sentido, el lugar podría ser físicamente uno, pero cada lugar será múltiple en sus sentidos singulares y subjetivos. El pueblo, la plaza, el camino, no los concebimos como entidades únicas sino como multiplicidades yuxtapuestas, ya que cada sujeto produce una en relación con "los otros"; y desde donde obrará a partir de la experiencia, sensibilidad, y lo universal (Passos, Kastrup y Tedesco, 2016). El lugar puede convertirse en plano común de la experiencia. La plaza, así, será el significante para poner en debate, y la multiplicidad, como yuxtaposición de realidades subjetivas, será el campo de intercambio y producción. Por eso, cuando hablemos de territorio estaremos siempre refiriéndonos a territorios singulares y colectivos.

En este texto trabajamos sobre dos cuestiones que nos convocaron desde una serie de experiencias transitadas: un proceso de investigación implicado y un proceso de producción de método en Cartografía Social. Para esto nos situamos en dos marcos de referencia: a) la filosofía de la diferencia (Deleuze y Guattari ) y b) el método de pesquisa cartográfica (Passos, Kastrup y Tedesco, 2016). Finalmente, desde la Cartografía Social tomamos los aportes de Montoya (2017), Carballeda (2016) y Andrade y Santamarina (2012), a los cuales sumamos experiencias y desarrollos propios (Diez Tetamanti y Chanampa, 2016; Diez Tetamanti, 2012, 2016 y 2018).

De manera que el proceso que relatamos en este artículo se hace desde un recorrido transitado en experiencias de Cartografía Social, tanto en proyectos de extensión como en investigación, que implica los dos marcos de referencia teórico-metodológicos mencionados más arriba.

Una parte de este proceso está extraída de Perspectivas de la Cartografía Social, experiencias entre extensión, investigación e intervención social (Diez Tetamanti y Chanampa, 2016).

\section{Nos encontramos como rizoma}

En 2012, nos encontramos en el Hospital Regional de Comodoro Rivadavia estudiantes y docentes de Geografía, Trabajo Social, Comunicación Social de la Universidad Nacional de la Patagonia San Juan Bosco y de la Tecnicatura en Salud Comunitaria del Ministerio de Educación del Chubut, para realizar un taller de Cartografía Social sobre problemáticas locales de intervención en salud comunitaria. Este encuentro fue el puntapié inicial para tejer una red en conjunto que abonaría, sin proponérselo, un doble sentido:

a) El abordaje de problemáticas de salud comunitaria desde un enfoque de pesquisa cartográfica aplicando Cartografía Social.

b) La producción de método de investigación implicada sobre la base de la práctica en extensión universitaria.

\section{El encuentro con el método cartográfico}

Denominamos nuestra metodología de abordaje en Cartografía Social como "de los encuentros" o gaücha, ${ }^{1}$ lo cual supone la comunión metodológica y de prácticas en una línea

1) La denominación incluye diéresis para vincular, en "portuñol" (lengua híbrida que toma elementos del portugués y español), las palabras gaucha (es) y gaúcha (pt), y sintetiza la relación entre tres grupos de trabajo de Pelotas (Brasil), La Plata y Comodoro Rivadavia (Argentina). 
cartográfica que une desde Pelotas, en Brasil, ${ }^{2}$ hasta Comodoro Rivadavia, pasando por La Plata ${ }^{3}$ en Argentina. En la creación del método hay inexactitud en el sentido en que lo expresan Deleuze y Guattari (1977), que se presenta como el punto exacto de lo que se quiere decir en un proceso que está en permanente creación: lo inexacto. El significante de cartografía explotó entre prácticas y modos de hacer en el $7^{\circ}$ Foro Latinoamericano de Memoria e Identidad (Montevideo) del grupo Signo, en 2010. Allí, la palabra cartografía nos encontró juntos en un taller de Cartografía Social. ¿Será lo mismo cartografía y Cartografía Social? ¿Tal vez era tan relevante conceptualizar como producir el encuentro? Cartografía capturó nuestros cuerpos en ese momento del taller y desplegó nuevos encuentros que se expandirían incorporando las nociones de cartografía de Deleuze y Guattari, trabajadas por los colegas brasileños, en nuestras prácticas de Cartografía Social en Argentina. Se produjo así un despegue del enfoque crítico que veníamos abordando hasta ese momento desde los aportes de la literatura de los iconoclasistas, ${ }^{4}$ las experiencias colombiana y amazónica ${ }^{5}$ sobre Cartografía Social, reterritorializando el marco teórico hacia la filosofía de la diferencia.

Esta marca de encuentro y producción de una Cartografía Social gaücha enriqueció nuestras posibilidades de aplicación, implicación, análisis, devenir y traducción en Cartografía Social.

Entre 2009 y 2011 se abrió una puerta para pensar que este modo de hacer Cartografía Social será siempre inacabado, por lo cual, el método, cual rizoma, podrá extenderse hacia formas, esquemas, planos y articulaciones inesperadas (ver Gráfico 1)

\section{Navegando el sudoeste del Chubut}

Las experiencias que se producen desde nuestro enfoque de Cartografía Social gaücha se constituyen como marcas en un mapa extensivo (Deleuze y Guattari, 1977) y producen permanentemente modificaciones en las prácticas que devienen de anteriores instancias. Por esto, cada instancia de intervención intercepta siempre una nueva materia a incorporar al método. Cada experiencia aporta una nueva manera de hacer en un proceso de transformación indefinido y con la singularidad de cada caso.

Podemos decir que desde 2011 hubo tres marcas que dieron cuerpo al método de Cartografía Social tal como lo entendemos. La primera fue la convocatoria a trabajar en conjunto con la Tecnicatura en Salud Comunitaria; la segunda, el taller en la municipalidad de Río Mayo en 2013; y la tercera, en ese mismo año, en Aldea Beleiro. Estas tres marcas no son únicas ni excluyentes pero sí dieron cuenta de tres procesos que resultan relevantes para el abordaje en Cartografía Social desde nuestra perspectiva.

2) En 2011 comenzamos a generar producciones en conjunto con el grupo Cidade + Contemporaneidade del LabUrb, dependiente de la Universidade Federal de Pelotas.

3) Desde 2008 trabajamos en conjunto con los colegas de Trabajo Social I de la Facultad de Trabajo Social de la Universidad Nacional de La Plata, con propuestas de Cartografía Social en el marco de las prácticas de intervención de estudiantes.

4) Iconoclasistas es el dúo formado por los autores del Manual de Mapeo Colectivo (Risler y Ares, 2013).

5) Pueden encontrarse referencias en Montoya Arango (2007), Andrade y Santamarina (2010), y en Nova Cartografía Social da Amazonia: novacartografiasocial.com.br 
Gráfico 1. Cartografía de los encuentros entre colegas de las Universidades de Pelotas, La Plata y Comodoro Rivadavia (UFPel, UNLP y UNPSJB).

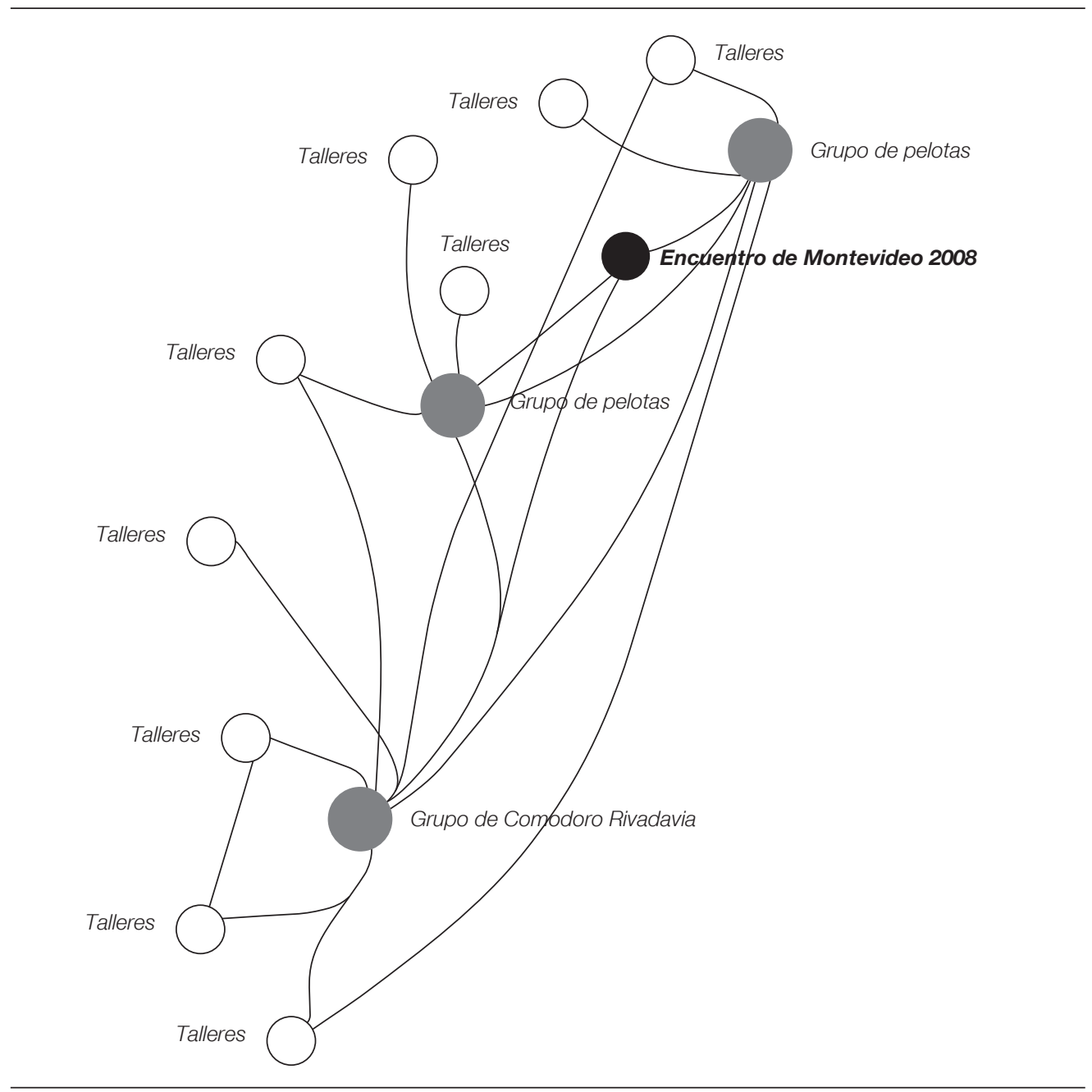

Fuente: elaboración propia.

\section{Juntos con la Tecnicatura en Salud Comunitaria}

La producción de metodología dentro de la universidad, en los marcos de la universidad, en el propio calco de las prácticas universitarias, a veces no facilita los procesos de transferencia, de devenires en otros territorios (que no sean los universitarios). Esta cuestión es también un problema hermenéutico, de interpretación, de traducción de los diversos textos que producimos en el seno de la universidad y para universitarios. Ante esto, los programas de extensión y transferencia de los últimos años, facilitados en gran medida por el ex Ministerio de Educación, ${ }^{6}$ contribuyeron al fortalecimiento del diálogo con la comunidad "extrauni- 
Gráfico 2. Cartografía de los encuentros y prácticas en Patagonia Central. Algunas experiencias que marcaron el hacer.

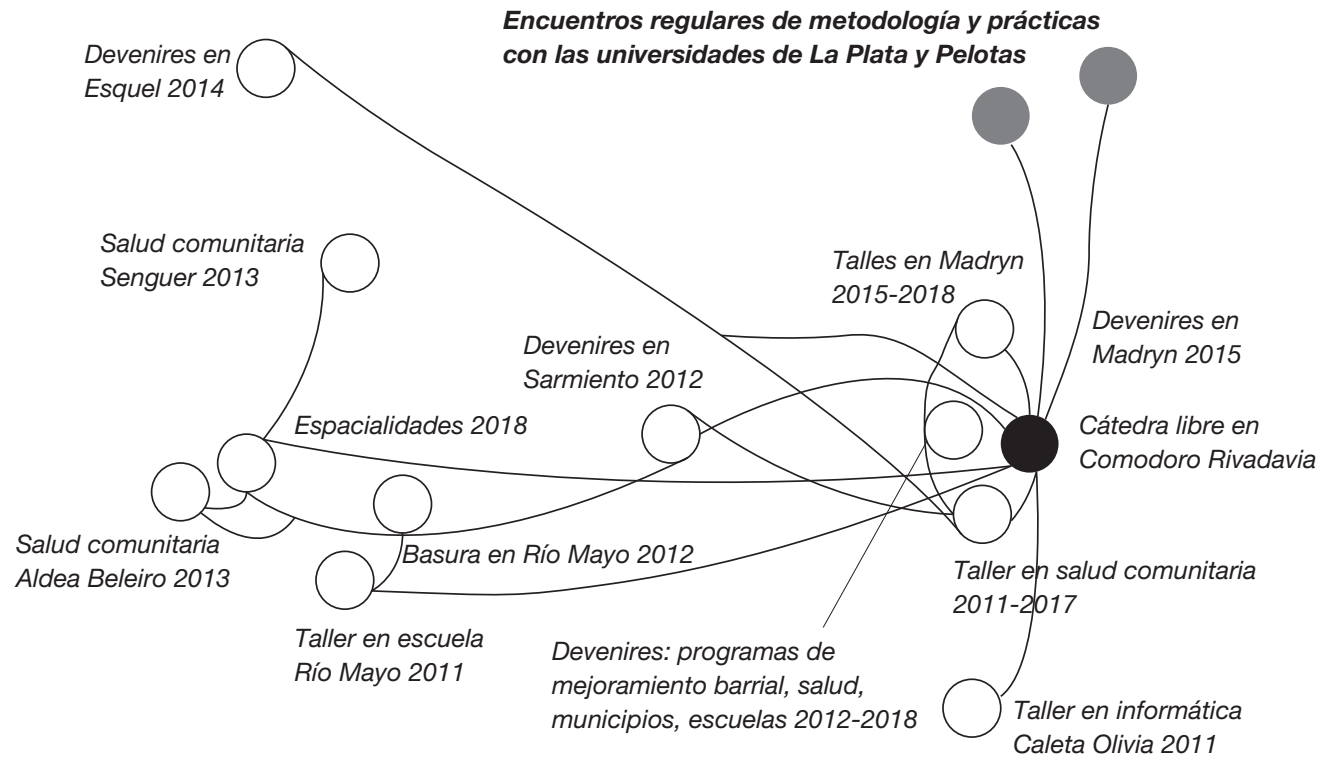

Fuente: elaboración propia.

versitaria", generando así nuevos territorios de construcción metodológica. La producción metodológica de Cartografía Social estuvo desde el inicio implicada con la comunidad.

Por eso, la invitación de los compañeros de la Tecnicatura en Salud Comunitaria, constituyó la posibilidad de iniciar proyectos "acompañando" procesos ya iniciados desde afuera de la Universidad.

El primer taller se desarrolló en el Hospital de Comodoro Rivadavia. Allí convergieron más de 20 técnicos en Salud Comunitaria, estudiantes de la Tecnicatura y diversos agentes de Salud Comunitaria de toda la provincia del Chubut. El taller se desenvolvió sobre una pregunta: ¿qué nos une en esta ciudad? ${ }^{7}$ Este interrogante nos permitió trabajar, por un lado, la idea de calco, que implica reproducir "lo conocido" sobre el mapa tradicional (Harley, 2001) $y$, al mismo tiempo, producir colectivamente en la hoja en blanco. ${ }^{8}$ Esta forma de abordaje habilitó la incorporación de la noción de multiplicidad, facilitada por el obraje de objetos únicos o múltiples, sobre un plano común.

Así, la noción de calco deleuziana se materializó sobre la cosmovisión de "ciudad" de Comodoro Rivadavia, que fue trazada en la "hoja en blanco", la cual funcionó articulando Aires, simplemente porque en ese momento no teníamos un mapa base. No obstante, las ventajas de la hoja en blanco serían descubiertas en la práctica más adelante. 
en el péndulo entre "calco" y "cartografía" (Deleuze y Guattari, 1977), sobreponiendo así el mapa tradicional con la "experiencia". De ese modo, la experiencia produjo un "plano común" (Passos, Kastrup y Tedesco, 2016), como lo vivido en la "ciudad" por los participantes del taller provenientes de otras ciudades. Por lo tanto, la ciudad nunca fue, ni en forma ni en contenido, la misma en cada grupo de cartógrafos sociales debido a dos cuestiones:

a) Los mecanismos que se despliegan, de traducción, negociación y representación sobre ciudad, experiencia y prácticas, es decir, el propio proceso de producción cartográfica en forma y contenido.

b) La multiplicidad (Deleuze y Guattari, 2004:214) entendida como los territorios reales que los cartógrafos ponen en juego y la yuxtaposición de experiencias singulares como insumo para producir un objeto consensuado: el texto-cartografía.

La experiencia inicial con los técnicos en Salud Comunitaria dejó un enorme aprendizaje que iría deviniendo en método a través de estas marcas:

a) No hay real a representar sino multiplicidad.

b) No hay forma única sino juego entre calco (del mapa tradicional) y experiencia.

c) La práctica colectiva es creadora, produce diferentes escalas ante una nominación (ciudad, no implicaba lo mismo en cuanto a límites, formas y objetos, para todos los grupos de trabajo... la multiplicidad se hizo cuerpo, línea y grafo).

d) Al finalizar el proceso, todos sabían más de todos, poniendo en juego la multiplicidad en un plano común.

e) El plano común se produce como rizoma a partir del proceso creativo.

\section{El taller de la basura en el municipio de Río Mayo}

¿Qué relaciones nos llevaron hasta Río Mayo? ¿Qué fuerzas en la práctica nos convocaron a abordar temas diversos desde Cartografía Social? La experiencia de la Tecnicatura en Salud Comunitaria en Comodoro Rivadavia nos derivó a otros encuentros con colegas de Río Mayo. La localidad está a más de 250 kilómetros de Comodoro Rivadavia y en las descripciones de los geógrafos podemos encontrar los datos que nos dicen que hay más de 2000 habitantes y menos de 3000 y que, además, el mundo riomayense se produce en un espacio compartido entre civiles, militares y gendarmes, más sus familias e invitados, que comparten el habitar Río Mayo. Estas clasificaciones están presentes en la descripción oral e implican límites a priori, calcados de antiguas descripciones traducidas, a su vez, de otras descripciones sucesivas. El primer taller que hicimos en conjunto fue propuesto por un grupo de trabajadores en Salud Comunitaria que tenía interés en abordar el problema de la basura. ¿Qué hacemos en Río Mayo con la basura? ¿Qué prácticas, relaciones y conflictos acontecen? ¿Qué hicimos, qué podemos hacer con la basura? Eran algunas preguntas motivadas por los anfitriones locales. Fue así que en un proceso de más de un mes de reuniones y producciones de dispositivos de abordajes ${ }^{9}$ generamos un instrumento para traducir las preguntas iniciales en una guía de trabajo. ${ }^{10}$ El taller fue organizado también por los anfitriones, por lo tanto la convocatoria y la propia difusión fue motivo de movilización de los colegas de 
Río Mayo. El día del taller, la guía de trabajo se hizo cuerpo en la dinámica producida en las experiencias anteriores. Ahora, por ejemplo, cuando en la guía indicábamos "vamos a dibujar Río Mayo", ya sabíamos que no habría solo proceso de calco sino de producción sobre las diferentes multiplicidades puestas en juego en el taller de Cartografía Social. Habría así muchos ríosmayos, y sobre ese material trabajaríamos.

Los cartógrafos sociales dibujaron, tradujeron y discutieron una multiplicidad de prácticas, relaciones y conflictos sobre la basura y su "manejo". La práctica de "quema" en domicilio y las bolsas voladoras por el viento generaron mucha polémica y críticas entre los cartógrafos sociales. Revisiones, culpas y acusaciones fueron diseminadas, y en ese momento sucedió algo singular. Alguien recordó que hacía algunos años se habían dispuesto cestos públicos de basura por la ciudad, pero que estos "habían sido incendiados por los jóvenes". "Esa idea de que los cestos no sirven porque los jóvenes les prenden fuego", dijo uno de los cartógrafos. "Es que los jóvenes no cuidan lo propio", agregó otro cartógrafo. El proceso de cartografiado se iba gestando a medida que la discusión avanzaba. Estaba en marcha un proceso de intertextualidad del cual no habíamos tomado nota. Había otro texto adyacente y en simultáneo. Otro cartógrafo recordó: "¡Esos cestos prendidos fuego tenían que ver con un conflicto de ese momento... había dos bandas en el pueblo que disputaban territorio... incendiar cosas era parte del conflicto! ¡Los jóvenes no son piromaníacos!".

El debate había producido, sobre una naturalización de jóvenes como incendiarios naturales, otras posibilidades. La memoria traía otros calcos que producirían nuevos sentidos de la práctica espacial. Colocar cestos de basura ya no sería imposible si los jóvenes no eran naturalmente piromaníacos, puesto que la frase "iHabía dos bandas en el pueblo que disputaban territorio... incendiar cosas era parte del conflicto!" modificaba las condiciones.

Esta experiencia reescribió nuestros modos de producir método. A partir de ese momento, utilizaríamos las guías, derroteros o cualquier otro instrumento de traducción entre la(s) pregunta(s) inicial(es) y el proceso de producción de Cartografía Social para generar resignificaciones del pasado y los acontecimientos. Comenzamos a trabajar con textos paralelos, tanto desde la oralidad como desde la escritura y el grafo. Pero también con los cuerpos, ya que, por ejemplo, en pleno proceso de cartografía algunos funcionarios de jerarquía preferían no trabajar en el suelo, como era dada la consigna para territorializar la práctica. ${ }^{11}$ Esto nos hablaba de que había, además de múltiples territorios yuxtapuestos en cada grupo de cartógrafos sociales, planos superpuestos, otras jerarquías y textos que podían leerse más allá del mapa. ¿El mapa social, sería un pretexto? ¿Simplemente el mapa es una parte más?

La experiencia en Río Mayo dejó estás marcas en el método:

a) La guía o el derrotero es un instrumento de traducción de las preguntas iniciales en el proceso de implicación e investigación.

b) El derrotero puede jugar con instancias de tiempo para cuestionar las prácticas, relaciones, conflictos, desde la multiplicidad, ya que no hay "una" instancia a representar sino planos a poner en yuxtaposición.

11) Desde esta experiencia, el trabajo en el suelo se planteó como parte del enfoque del taller. Si bien existen siempre limitaciones singulares para el trabajo en esa posición, la práctica desde el suelo implica además "producir un territorio" (Camels, 2004), lo que a su vez permite deconstruir territorios instituidos al producir un nuevo texto del cuerpo que se incorpora a la producción colectiva (Diez Tetamanti, 2018:74). 
c) El mapa es texto pero no es el único. Aunque el mapa es producido colectivamente y desde subjetividades en consenso y disenso, también los otros planos producen texto: cuerpo, oralidad, escritura. Más adelante incorporaríamos entonces la denominada "hoja de bitácora", que nos permitiría tomar nota y cuerpo de estos otros procesos, además de video, fotografía y expresiones del cuerpo.

Desde este taller en Río Mayo, el trabajo en el suelo y la bitácora ${ }^{12}$ se sumaron como instrumentos del método, así como el derrotero se consolidó como elemento central de traducción entre pregunta $>$ sujetos $>$ colectivo $>$ mapa $>$ sistematización $>$ devenires.

\section{Los partos en Aldea Beleiro}

Llegamos a Aldea Beleiro, una localidad con casi 200 habitantes y a cinco kilómetros de Chile. ${ }^{13}$ Desde que iniciamos nuestro trabajo con los colegas de la Tecnicatura en Salud Comunitaria durante la experiencia del Hospital Regional de Comodoro Rivadavia, se trazó una cartografía en el acompañamiento de problemáticas compartidas. En esto se sumaban agentes de Salud Comunitaria de otras localidades de la zona, como Lago Blanco, Sarmiento, Río Senguer, Aldea Apeleg y Río Mayo. Cada localidad, una singularidad y una marca a seguir. Un mapa de instancias compartidas en el proceso de formación de los técnicos en Salud Comunitaria, que acompañamos con diversos talleres de trabajo.

Ya habíamos estado visitando Río Mayo y Aldea Beleiro en varias ocasiones. El puesto sanitario siempre nos esperaba con buenos mates y nuevas experiencias. La enfermera y la trabajadora en Salud Comunitaria estaban dispuestas a abordar siempre nuevas preguntas. En 2013, fue la oportunidad inicial para estar una semana compartiendo con vecinos problemáticas con relación al acceso a la salud. Así es que, luego de varias entrevistas y planificaciones con las compañeras del puesto sanitario, decidimos plantear un taller de Cartografía Social.

Un viernes, en el Club de Madres, bien cerca del puesto sanitario, estábamos dispuestos para trabajar en ese taller con los invitados por las compañeras. Eran varios chicos de la escuela primaria, maestras y madres, que estaban ansiosos por dibujar y cartografiar cuestiones vinculadas al acceso a la salud. El derrotero que habíamos producido con las compañeras del puesto sanitario se esquematizaba como traducción de esa pregunta inicial: ¿cuáles son los problemas de accesibilidad a la salud en Aldea Beleiro? De allí surgieron otras preguntas como: ¿cómo se realizaban las prácticas en el pasado? ¿Cómo accedemos a tratamientos de rutina, medicamentos, emergencias? El derrotero invitaba a dibujar en cada etapa estas preguntas traducidas en lo que denominamos "aspectos".

El taller inició y la cartografía fluyó entre Aldea Beleiro, Río Mayo, Comodoro Rivadavia y Chile. Las singularidades puestas en común sobre "acceder a la salud" eran vertidas en el papel tanto por los niños como por los adultos con una agilidad admirable. Distancias, nieve y estado de los caminos se imponían en conjunto con los elevados costos de trasladarse más de 400 kilómetros para llegar a un hospital. En un momento llegó la instancia de hablar del pasado. ¿Cómo se realizaban las prácticas en el pasado? Las madres no dudaron en 
conversar sobre los partos. El tema estaba instalado desde el inicio de la cartografía. Hacía 13 años que no nacían niños en el pueblo y eso constituía un problema. En el derrotero estaba hecha la invitación a dibujar una práctica del pasado en color azul. Los partos se diseminaron entre las casas de familia con matronas, el puesto sanitario y la enfermería de la Gendarmería Nacional. Una chica de no más de 20 años preguntó: "¿Antes se podía parir acá?". El debate inició. La cartografía había puesto sobre el plano común un tema silenciado pero movilizante. Ahora las madres embarazadas tenían que parir a 400 kilómetros de Aldea Beleiro. ¿Por qué hoy no se podía parir en la localidad y antes sí? La enfermera comentó sobre nuevas legislaciones que impedían parir en casas de familia y hasta en el mismo puesto, e incluso en el propio Hospital de Río Mayo, a poco más de 100 kilómetros. Se requerían complejidades para la atención que solo se encontraban en Comodoro Rivadavia.

"¿Queremos parir de nuevo acá!", dijo otra mamá. La cartografía detuvo su dibujo para internarse en el habla, las experiencias pasadas y los intercambios sobre porqués y cómos. La frase "iQueremos parir de nuevo acá!" marcó un cambio rotundo en nuestros modos de hacer cartografía. Habíamos puesto al pasado en cartografía para que, sobre la obra de ese evento pretérito, se cuestionara el presente. Pero además... el debate nos estaba diciendo que esos temas, como el de los partos ayer y hoy, requerían más diálogo. Había una demanda para hablar. Las mamás decidieron hacer una carta dirigida al gobernador. La exigencia de "volver a parir en el lugar" estaba planteada. Desde ese momento, cada parto tendría la carga de una posibilidad. El devenir parto-local había cobrado una fuerza que desde entonces debía ser trabajada en conjunto, entre las compañeras del puesto sanitario y las mamás.

La experiencia de Aldea Beleiro fue para nuestro grupo una marca en la posibilidad de trabajar otras dinámicas sobre el instrumento derrotero. Sobre lo experimentado en talleres anteriores, ahora el abordaje del pasado se ponía en marcha para pensar modificaciones en el presente. Poner en juego una práctica, como aquella de la basura en Río Mayo, no solo cuestionaba eventos del pasado desde la multiplicidad sino que hacía emerger preguntas: si antes sí, ¿por qué ahora no? ¿Cómo fue el cambio? Si cambió, ¿por qué no puede cambiar otra vez? La experiencia Aldea Beleiro dejó estas marcas en el método:

a) En Cartografía Social, el juego con el tiempo es un modo de articular posibilidades, intenciones y deseos.

b) La agencia del pasado pone en consideración las transformaciones, devenires y acciones presentes.

c) La multiplicidad en las dinámicas temporales cuestiona toda naturalización y abre la puerta para proponer cambios.

\section{Consideraciones para continuar}

Los tres procesos de acompañamiento e implicación con los técnicos en Salud Comunitaria, el abordaje y producción metodológica de Cartografía Social y la generación de campos de investigación en esas líneas constituyeron indisolublemente una deriva. El camino emprendido siempre fue guiado por preguntas producidas en contextos de diálogo, en donde la experiencia se dispuso en líneas horizontales. Así, por ejemplo, en 2015 iniciamos en conjunto con los técnicos en salud comunitaria un programa de intercambios de experiencias rural-urbano. En este marco, agentes de salud de áreas rurales y urbanas pasaron una 
semana de experiencias de práctica en otros territorios (Diez Tetamanti y Armesto, 2016). Una agente de salud de Comodoro Rivadavia en Aldea Apeleg, una agente de Sarmiento en Comodoro, y así sucesivamente. Los cruces se multiplicaron y, a principios de 2018, se desarrolló un programa más amplio que ocupó más aldeas y centros de salud. ${ }^{14}$ Sobre las experiencias se generaron relatos, ${ }^{15}$ videos y fotografías, los cuales se encuentran en pleno proceso colectivo de sistematización.

En 2018 iniciamos un proceso de investigación implicada ${ }^{16}$ en tres localidades del sudoeste del Chubut: Aldea Beleiro, Lago Blanco y Ricardo Rojas, localidades en donde creamos un dispositivo de entrevistas cartográficas (Tedesco, 2016). También incorporamos la producción de dioramas ${ }^{17}$ socializados con el propósito de poner en cuestión el uso del espacio y el tiempo y una técnica a la cual denominamos "sociocartograma". Esta implica, en el seno de la entrevista, producir una cartografía entre entrevistado y entrevistador con el propósito de hacer surgir nuevos sentidos espaciales e intercambio de información en una instancia de exploración y profundización de la investigación social. Para ello se crean nuevos territorios, tanto para el entrevistado como para el entrevistador, y se establecen en la hoja en blanco y compartida el terreno para crear "otros" límites, nominaciones y traducciones.

Después de siete años trabajando en estas tierras, Ilamadas Patagonia Central, las clasificaciones podrían haberse modificado. Nuevas preguntas nos interpelan: ¿qué significan nuestras preocupaciones urbanas y académicas sobre estos mundos rurales? ¿Qué cosmovisiones sobre las problemáticas impuestas se originan en el lugar? ¿Cómo se producen territorios entre la experiencia local del cuerpo y las traducciones que hacemos desde lugares distantes? ¿No es la problematización una construcción a partir de una mirada ajena, que no padece la experiencia local del cuerpo, pero interpreta traduce y genera texto sobre lo observado? Estos temas nos ocupan actualmente y, para ello, necesitaremos mayores posibilidades para implicarnos, aprendiendo con el otro y deconstruyendo nuestras propias y cómodas clasificaciones académicas. Desde esas preguntas puestas en plano común, pretendemos "andar" con los vecinos de las localidades y producir Cartografías Sociales, método y multiplicidades.

\section{Referencias bibliográficas}

Aínsa, F (2014). Nueva cartografía de la pertenencia. La pérdida del territorio en la narrativa latinoamericana. Revista Iberoamericana Iberoamericana, XIV(54), 111-126. Recuperado de https://journals.iai.spk-berlin.de/index.php/iberoamericana/article/viewFile/1086/768. pp. 111-126 (consultado el 20/12/2017).

Andrade, H. y Santamaría, G. (2010). Cartografía social: el mapa como instrumento y metodología de la planeación participativa. Fundación Aldeas. Recuperado de http://fundaaldeas.org/index.php?option=com_content\&view=article\&id=91:andrade-sh-y-santamaria-ghelena-andrade-m (consultado el 20/8/2018).

14) Este trabajo se encuentra en prensa y recopila las experiencias en diferentes textos de agentes de salud comunitaria que llevaron adelante prácticas en territorios diferentes a los de su cotidianeidad.

15) Puede verse un pequeño relato en video en: https://youtu.be/ihyLg-ZttdM, editado por Mónica Baéza.

16) Se trata del PICT 4092-2016 titulado: "Estrategias y dispositivos comunitarios y estatales en procesos de desarrollo territorial de pequeñas localidades y zonas rurales dispersas del sudoeste de la provincia de Chubut".

17) Los dioramas a partir de Hagerstrand (1982), realizados en producción colectiva como herramienta para la socialización del empleo del tiempo en comunidades. 
Bondel, C.S. y Vazquez, A. (2016). Multiterritorialidad en la Patagonia rural esteparia: Destinos de la tierra, ausentismo y problemáticas emergentes. Revista Universitaria de Geografía, 25(2), 103-132. Recuperado de http://bibliotecadigital.uns.edu.ar/scielo.php?script=sci_arttext\&pid=S1852-42652016002200005\&lng=es\&nrm=iso (consultado el 13/12/2017).

Camels, D. (2004). Espacio habitado. Buenos Aires: Novedades Educativas.

Carballeda, A. (2016). Cartografías e Intervención en lo Social. En Escenarios sociales, intervención y acontecimiento (Capítulo 4). Recuperado de http://www.margen.org/epub/acontecimiento. pdf (consultado el 9/4/2017). Careri, F. (2014). Walkscapes ten years after. Revista de Estudios Urbanos y Ciencias Sociales, 4(1), 207-213. Recuperado de http://www2.ual.es/urbs/index.php/urbs/article/view/careri (consultado el 20/12/2017).

Chanampa, M. et al. (2015). Accesibilidad a la salud y estrategias de movilidad. Caso aldea Beleiro. Informes Científicos-Técnicos UNPA, 7(1), 54-77. Recuperado de http://ict.unpa.edu.ar/journal/index.php/ ICTUNPA/article/view/ICT-UNPA-98-2015. doi: http://dx.doi.org/10.22305/ict-unpa.v7i1.113 (consultado el 20/12/2016).

Deleuze, G. y Guattari, F. (1977). Introducción: Rizoma. Mil Mesetas. Capitalismo y esquizofrenia. Barcelona: Pre-textos.

(2004). Mil Mesetas. Capitalismo y esquizofrenia. Barcelona: Pre-textos.

Diez Tetamanti, J.M. (2014). Hacia una geografía comunitaria: abordajes desde Cartografía Social y sistemas de información geográfica. EDUPA.

(2018). Cartografía Social, teoría y método. Buenos Aires: Biblos.

Diez Tetamanti, J.M. y Armesto, S. (2016). Salud Comunitaria, territorio de relatos en Patagonia. EDUPA.

Diez Tetamanti, J.M. y Chanampa, M.E. (2016). Perspectivas de la Cartografía Social, experiencias entre extensión, investigación e intervención social. Revista +E versión digital, (6), 84-94. Santa Fe, Argentina: Ediciones UNL.

Diez Tetamanti, J.M. y Escudero, B. (2012). La construcción de un dispositivo de intervención a través de Cartografía Social. En Diez Tetamanti, J.M. et.al. Cartografía Social: investigación e intervención desde las ciencias sociales, métodos y experiencias de aplicación. EDUPA

Diez Tetamanti, J. y Rocha, E. (2016). Cartografía social aplicada a la intervención social en barrio dunas, Pelotas, Brasil. Revista Geográfica de América Central, 2(57), 97-128. https://doi.org/10.15359/rgac.57-2.4 Hagerstrand, T. (1982). Diorama, path and project. Tijdschrift voor economische en sociale geografie, (73), 323339. doi:10.1111/j.1467-9663.1982.tb01647.x

Harley, J. (2001). The new nature of maps: essays in the history of cartography. Baltimore: The Johns Hopkins University Press.

Hidegger, M. (1984). Caminos del Bosque. Barcelona: Alianza editorial.

Montoya Arango, V. (2007). El mapa de lo invisible. Silencios y gramática del poder en la cartografía. Revista Universitas Humanística, (063). Bogotá: Pontificia Universidad Javeriana.

Passos, E.; Kastrup, V. y Tedesco, S. (2016). Pistas do método da cartografia 2. Porto Alegre: Sulina. Risler, J. y Ares, P. (s/f). Manual de mapeo colectivo recursos cartográficos críticos para procesos territoriales de creación colaborativa. Buenos Aires: Tinta Limon.

Tedesco, S. (2016). Pista da Entrevista. Passos, E.; Kastrup, V. y Tedesco, S. (2016). Pistas do método da cartografia 2 (pp. 92-127). Porto Alegre: Sulina. 